\title{
Service providers' perspectives on barriers of healthy eating to prevent obesity among low-income children attending community childcare centers in South Korea
}

Citation for published version (APA):

Park, J., Ten Hoor, G. A., Cho, J., \& Kim, S. (2020). Service providers' perspectives on barriers of healthy eating to prevent obesity among low-income children attending community childcare centers in South Korea: A qualitative study. Ecology of Food and Nutrition, 59(3), 311-328.

https://doi.org/10.1080/03670244.2020.1722948

Document status and date:

Published: 01/01/2020

DOI:

10.1080/03670244.2020.1722948

Document Version:

Publisher's PDF, also known as Version of record

\section{Document license:}

Taverne

Please check the document version of this publication:

- A submitted manuscript is the version of the article upon submission and before peer-review. There can be important differences between the submitted version and the official published version of record.

People interested in the research are advised to contact the author for the final version of the publication, or visit the DOI to the publisher's website.

- The final author version and the galley proof are versions of the publication after peer review.

- The final published version features the final layout of the paper including the volume, issue and page numbers.

Link to publication

\footnotetext{
General rights rights.

- You may freely distribute the URL identifying the publication in the public portal. please follow below link for the End User Agreement:

www.umlib.nl/taverne-license

Take down policy

If you believe that this document breaches copyright please contact us at:

repository@maastrichtuniversity.nl

providing details and we will investigate your claim.
}

Copyright and moral rights for the publications made accessible in the public portal are retained by the authors and/or other copyright owners and it is a condition of accessing publications that users recognise and abide by the legal requirements associated with these

- Users may download and print one copy of any publication from the public portal for the purpose of private study or research.

- You may not further distribute the material or use it for any profit-making activity or commercial gain

If the publication is distributed under the terms of Article $25 \mathrm{fa}$ of the Dutch Copyright Act, indicated by the "Taverne" license above, 


\title{
Service Providers' Perspectives on Barriers of Healthy Eating to Prevent Obesity among Low- income Children Attending Community Childcare Centers in South Korea: A Qualitative Study
}

\author{
Jiyoung Park, G. A. Ten Hoor, Jeonghyun Cho \& Soobin Kim
}

To cite this article: Jiyoung Park, G. A. Ten Hoor, Jeonghyun Cho \& Soobin Kim (2020) Service Providers' Perspectives on Barriers of Healthy Eating to Prevent Obesity among Low-income Children Attending Community Childcare Centers in South Korea: A Qualitative Study, Ecology of Food and Nutrition, 59:3, 311-328, DOI: 10.1080/03670244.2020.1722948

To link to this article: https://doi.org/10.1080/03670244.2020.1722948

曲 Published online: 05 Feb 2020.

Submit your article to this journal

Џlll Article views: 274

Q View related articles $\square$

View Crossmark data ¿

Citing articles: 2 View citing articles ¿ 


\title{
Service Providers' Perspectives on Barriers of Healthy Eating to Prevent Obesity among Low-income Children Attending Community Childcare Centers in South Korea: A Qualitative Study
}

\author{
Jiyoung Park $\mathbb{B}^{\mathrm{a}}$, G. A. Ten Hoor $\mathbb{B}^{\mathrm{b}}$, Jeonghyun Cho $\mathbb{B}^{\mathrm{a}}$, and Soobin Kim ${ }^{\mathrm{c}}$ \\ aDepartment of Nursing, Institute of Health Science, College of Medicine, Inje University, Busan, South \\ Korea; 'Deprtment of Work \& Social Psychology, Maastricht University, Maastricht, The Netherlands; \\ 'School of Social Work, University of Pittsburgh, Pittsburgh, Pennsylvania, USA
}

\begin{abstract}
This study aimed to identify individual and socio-ecological barriers in managing healthy eating among low-income children from the perspective of community childcare (CCC) center workers $(n=18)$ through focus group interviews. They perceived the increase in obesity among low-income children. The interviews revealed that the child's eating habits are affected by not only individual determinants including self-regulation and risk awareness but also environmental factors such as family, CCC centers, policy and social structure. To enhance children's health and behavior, it is necessary to consider the interactions among systems at a variety of levels, for example, local community and health care policies.
\end{abstract}

\section{KEYWORDS}

Feeding behavior; focus groups; health status disparities; pediatric obesity

\section{Introduction}

In this study, we examine service provider's perspectives on barriers of healthy eating, to prevent obesity among low-income children attending community childcare (CCC) centers. Obesity is more prevalent in children of lower socioeconomic status (SES) compared to their higher SES counterparts. In the United States, in $2015-2016,40.1 \%$ of boys and $43.8 \%$ of girls were reported to be overweight or obese, but among children from households with an income of less than $\$ 20,000,50.4 \%$ of boys and $51.3 \%$ of girls were overweight or obese (World Obesity 2018). In South Korea, the childhood obesity rate has been increasing steadily from $11.6 \%$ in 2007 to $17.3 \%$ in 2017 (Oh et al. 2018). In particular, the obesity rate in school-aged children from low-income group is $20.3 \%$, which is two times higher than general school-aged children (10.1\%) (Jang 2019). This shows income disparities of childhood obesity in South Korea.

Childhood obesity is associated with poor eating habits, such as the consumption of sugary beverages, as well as low-nutrient, high-calorie, and

CONTACT Jeonghyun Cho jhcho@inje.ac.kr $\Theta$ Dept. of Nursing, Institute of Health Science, College of Medicine, Inje University, 75, Bokji-ro, Busanjin-gu, Busan 47392, South Korea

(C) 2020 Taylor \& Francis Group, LLC 
high-fat foods (Magee, Caputi, and Iverson 2013; Trofholz et al. 2017). Poor eating habits occur more severely among children from low-income families. For example, when compared to the Nutrition Quotient (NQ) score, Korean standard measures to evaluate the children's eating behaviors, the lowincome children's score is lower than general children has (58.1vs. 64.9) (Jang 2019). For these families, price is the most influential factor in foodpurchasing decisions (Dachner et al. 2010), which leads them to consume cheap foods low in nutrition and high in calories and fat, e.g. fast foods, rather than healthy foods (Hernandez, Montana, and Clarke 2010; Kim 2009). Moreover, the low-income parents in South Korea experience lack of attention of eating management for their kids due to work-family balance. Also, their bad eating habits create unhealthy eating environments at home (Park 2019). Therefore, efforts are needed to improve the eating behaviors of low-income children.

In South Korea, CCC-centers are an integral part of the lives of children from low-income families. CCC-centers are nationwide community-level childcare facilities providing low-income children with afterschool services including feeding, protection, education, cultural experience, and emotional support (Kim 2013). Currently, there are 4,189 centers in operation. Among the various services they provide, feeding is considered one of the most important by both children and their parents (Suh and Rho 2013). Moreover, as the centers offer children snacks and dinner, the service providers often decide the menu, cook, and distribute food to the children (Park and Jung 2017) thereby influencing children's eating habits. Thus, to understand childhood obesity in the lowincome group and develop obesity prevention programs, it is essential to determine service providers' perceived difficulties in managing low-income children's eating habits. So far, there has been no research on this topic.

There is a growing interest in the influence of 'environment' in child health promoting behaviors including eating habits (Haerens et al. 2009; Kim et al. 2019; Park 2018). Children's behavior is influenced not only by individual psychological, physiological, and cognitive development processes but also by various environmental agents, such as the family, peers, the school environment, and community organizations (Rauch and Lanphear 2012). To explain the influence of 'environment' in eating behaviors of lowincome children, the current study employed an ecological approach for understanding multiple levels of factors and barriers influencing health behavior, from the individual, family, and social network level to the organization, community, and societal level (Kok, Peters, and Ruiter 2017; Sallis, Owen, and Fisher 2015). The ecological model guided the overall study including the questioning route and data analysis. In this study, obstacles in managing low-income children's obesity are identified from the service providers' point of view. The results will be used for developing interventions 
and policies to relieve health disparities in childhood obesity, and as a basis for future research.

\section{Materials \& methods}

Focus group interviews were conducted with CCC-center workers, including managers and social workers.

\section{Study design and participants}

This study is part of a needs assessment to develop an obesity prevention program for low-income children attending CCC-centers in South Korea. We identified the perspective of stakeholders, overweight and obese children attending CCC-centers, primary caregivers, service providers and assistant cooks at CCC-centers, on childhood obesity in low-income groups (Lee et al. 2017; Park, Hwang, and Cho 2018). To investigate service providers' perceived barriers in improving healthy eating among children, we applied a qualitative research methodology involving focus group interviews, using a single-category design to investigate the perspectives of one type of participant; Krueger and Casey (2014) suggest the inclusion of at least three groups to reach theoretical saturation. Three focus group interviews with 18 service providers were conducted, and no new information was gathered during the final interview. Participants were recruited through purposive sampling with the help of the CCC-centers association in the community. The president of the association contacted to each center director and explained the purpose and method of this study. And then, the director of center recruited social workers who had interested in the study. There was 20 CCC-centers in the community. Each center has one director and one or two social workers. Among them, 12 center directors and 6 social workers from 13 centers participated. The participants were interviewed in three groups: two for directors and one for social workers. The social workers' interviews took place in a separate location from the directors, which allowed the social workers to express their experiences more openly.

\section{Procedure}

Group interviews were conducted in September 2016. Before collecting data, the researchers provided participants with the following information: purpose of the study; process and duration of the interviews; and request to audio record each focus group. In addition, they were assured of confidentiality and anonymity, and informed that the interview data would only be used for this study, and that they could withdraw at any point. After offering 
the information, the researchers received written consent from all participants. One day before the interview, this information was again provided via text message. Participants filled out a questionnaire on their demographic characteristics. They were provided with gift cards after the interviews.

The interviews took place at a meeting room of the Childcare Support Center in the community, and light refreshments were served to create an environment conducive to conversation. Each group's interview took approximately 1.5-2 hours. The interviews were led by a moderator (principal investigator) experienced in conducting focus group interviews and has been working for CCC-centers for more than five years. The moderator used 'pause and probe' during the interviews (Krueger and Casey 2014), to encourage the participants to fully express their personal experiences and opinions. An assistant moderator observed and recorded the atmosphere and participants' nonverbal responses during the interviews. Field notes were completed after each interview, to understand the context of participants' statements. The interview questions were based on previous studies reflecting ecological approaches (Haerens et al. 2009; Kim et al. 2019) and comprised semi-structured and open-ended questions as:

- Do you think childhood obesity in low-income families is a problem in your community?

- What are the children's eating habits at your CCC-center?

- Which factors contribute to or restrict children's healthy eating at your CCC-center?

- Who do you think is responsible for reducing the rate of childhood obesity in low-income families?

- What suggestions do you have for changes at home, in schools, and in the community that would help children eat healthy foods?

The study was approved by the institutional review board of the researchers' university (IRB number: 2016-08-003-001).

\section{Data analysis}

The interviews were digitally recorded and transcribed verbatim. Transcribed data was verified by one author, who was a moderator of each focus group, and was checked for accuracy. We followed framework analysis (Ritchie and Spencer 1994), with five key stages: familiarization, identifying a thematic framework, indexing, charting, and mapping \& interpretation. The researchers repeatedly read the complete transcripts and the summary notes added by the moderators during and after the interviews. The researchers then independently made notes to mark important ideas and concepts arising from the text to identify a thematic framework. Subsequently, an indexing and 
charting process was conducted for data reduction. During this stage, three researchers had five meetings to compare and contrast their notes to reach consensus on labels for the (sub)themes. Themes were arranged based on the ecological model; individual, interpersonal, organizational/community, and system. Quotes were selected to express the themes and were independently translated into English by two experts who speak both Korean and English. After the translations the adequacy of the translation was confirmed. Finally, the results were fully reviewed and a figure was created to show the relationships between the themes. Analysis was completed by hand. To ensure the rigor of the results, we conducted a member check with one participant to confirm the agreement of their intention with the analyzed contents.

\section{Results}

In total, 18 service providers were interviewed. Table 1 showed general characteristics of participants. The interviews were transcribed and analyzed, resulting in perceptions and recommendations on the child's level (individual), home situation (interpersonal), CCC-center (organizational/community), and system level (Figure 1).

\section{The individual level}

\section{Observations}

The service providers perceived the increase of obesity as a common problem in children from low-income families. Also, the problem of underweight children from low-income families was identified:

So many kids are obese ... Last year, there were only a few, but this year the numbers have increased a lot. I'm very worried. [P2-1]

Table 1. General characteristics of participants.

\begin{tabular}{|c|c|c|c|c|}
\hline & & $\mathrm{N}(\%)$ & $\mathrm{M}(\mathrm{SD})$ & Range \\
\hline \multirow[t]{2}{*}{ Sex } & Male & $3(16.7)$ & & \\
\hline & Female & $15(83.3)$ & & \\
\hline Age (years) & & & $46(11)$ & $29-63$ \\
\hline \multirow[t]{2}{*}{ Education } & College & 15 (83.3) & & \\
\hline & Graduate school & $3(16.7)$ & & \\
\hline \multirow[t]{2}{*}{ Position } & Director & $12(66.7)$ & & \\
\hline & Social worker & $6(33.3)$ & & \\
\hline $\begin{array}{l}\text { Experiences for social } \\
\text { work facilities } \\
\text { (months) }\end{array}$ & & & $89(53)$ & $20-209$ \\
\hline $\begin{array}{l}\text { Experiences for } \mathrm{CCC}^{*} \text { - } \\
\text { centers (months) }\end{array}$ & & & $67(47)$ & $7-168$ \\
\hline
\end{tabular}




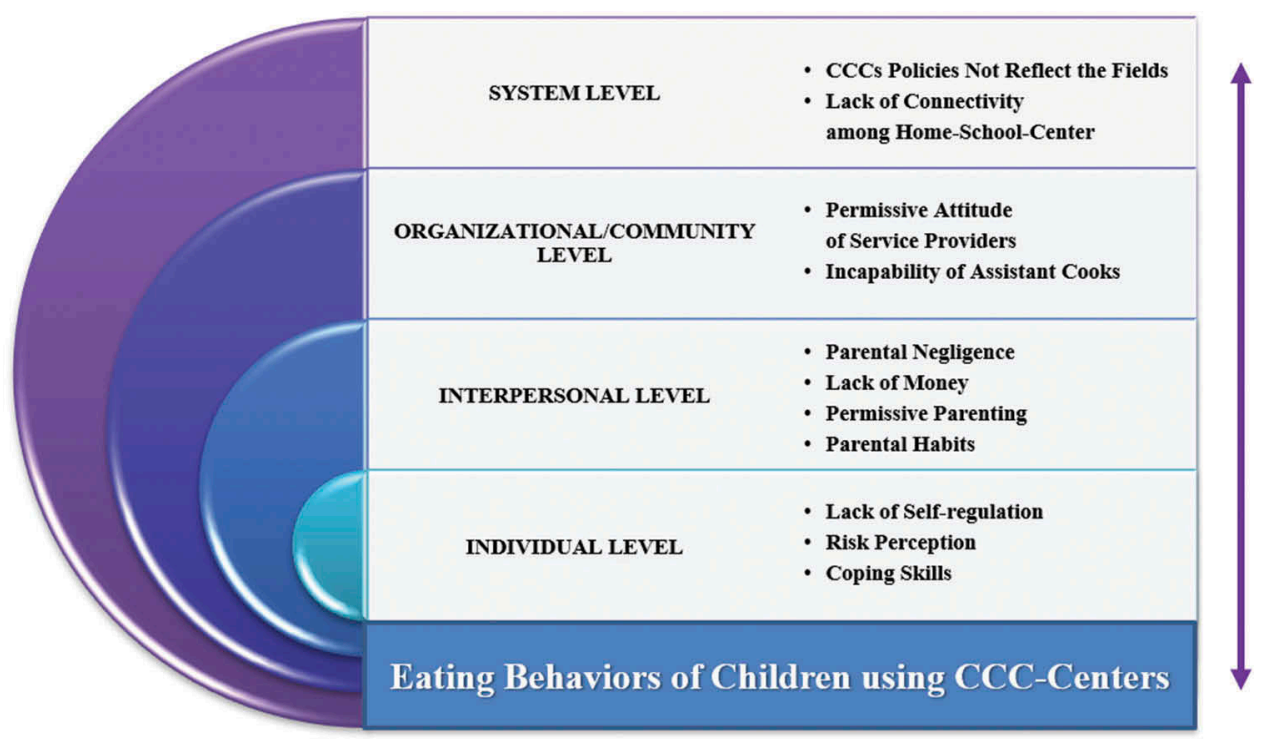

Figure 1. Barriers to improving healthy eating among low-income children attending community childcare centers. CCC = Community childcare.

The thin child is being neglected at home. He is in second grade, but his weight and physique are only at the level of a six-year-old child. There is this case and other cases of child neglect, but there are also children who are seriously obese. [P3-1]

At the individual level, the service providers commented on the eating habits of children from low-income families. These ranged from picky eating to adding unhealthy additives (sauces or salt) and eating too fast.

While some kids are very picky and only want to eat meat, others have a more adult taste. There are also kids who would mix the rice and namul (a variety of edible grass or seasoned herbal dishes made from them) in the soup just to scarf it down. [P2-4]

One of the bad eating habits is that they eat very salty food. One kid eats soy sauce alone like it is some soup. I tried to stop him from doing that, but he wouldn't listen to me. He even pours the soy sauce on his rice and eats it like a soy sauce soup. [P2-3]

The most prominent barriers identified by the service providers were children's lack of self-regulation, risk perception, and coping skills.

\section{Self-regulation}

The service providers mentioned that the children have no self-control when it comes to eating, which leads to eating too much food. "Kids take third and fourth servings and eat continuously [...] but they have no control and don't know when to stop." [P1-4] 


\section{Lack of risk perception}

The children attending the CCC-centers do not feel vulnerable or susceptible to health issues related to unhealthy eating. The service providers observed that children are neither aware of what they eat nor of the risks involved with high-fat or salty foods given the way they eat food.

I told the children that eating fried and salty foods can lead to diseases later in life, but they just make rough remarks like 'So, I'll just die.' I don't know how to respond to that. [P2-3]

\section{Lack of coping skills}

The service providers also expressed concern regarding stress and emotional problems (lack of love, loneliness, and anger). They believe that there is a causal relation between a child's immature way of coping and unhealthy eating behaviors.

He is always alone. Even if someone is beside him, he thinks he is all alone. And that is why he is eating all the time. He is eating because of stress and is trying to solve everything by eating. I think this problem comes from his environment. The environment of the children attending CCC-centers is not good. [P1-6]

One of our students has so much built-up anger. Perhaps this is the reason she prefers salty food and scarfs down the side dish. I think she is releasing her anger through this kind of eating behavior. [P2-3]

\section{The interpersonal level}

At the interpersonal level, the service providers explained that the home environment was the most influential environment leading to unhealthy behaviors and an unhealthy weight of the child. In the absence of primary caregivers, who are at work, children attending CCC-centers are often left alone at home, where food such as ramen, bread, and confectionary makes up their diet.

The mothers are engaged in economic activities late into the night and leave the children unattended. Naturally, the children eat ramen when they get hungry. As there is limited parental supervision, the children just eat what they can cook. [P1-3]

Such an environment of neglect often leads to children skipping breakfast or not eating enough, which in turn, leads to binge eating.

It would be nice if the primary caregivers paid a little more attention. Because they are so busy, they just tell the children to eat or wake them too late, making them skip breakfast altogether. Then, by lunch time, the children get so hungry that they end up eating too much. [P2-1] 


\section{Lack of money}

The participants stated that the parents of children attending CCC-centers often have economic difficulties. Therefore, they are affected by food prices and tend to purchase instant foods that are relatively inexpensive.

The children's families are generally inferior to other families in terms of economic level. There are many households where mothers as well as fathers work. Owing to their economic situation, they buy instant foods that are relatively cheaper. [P2-3]

\section{Parenting}

The service providers reported that the primary caregivers and grandparents are permissive about the food children choose and that this kind of parenting leads to undesirable eating habits such as picky eating.

The primary caregivers tend to be permissive, allowing exceptions. For example, since a lot of the children here come from single-parent households, they tend to have this attitude of finding excuses for the child such as, 'But he doesn't have a dad ... But he doesn't have a mom ... So, it's OK to eat this way.' [P3-4]

Additionally, the food preferences and eating habits of the primary caregivers can affect the children.

Children think that enjoying eating is a pleasure of life. However, when we look at the children who eat excessively and are obese, their mothers are all overweight. The whole family enjoys eating. [P1-7]

\section{The organizational/community level}

The service providers also agreed that there are certain aspects and situations that can be improved at the CCC-centers. For example, the participants were aware that it is educationally necessary to limit the amount of food children eat. However, the participants felt bad for the children who could not have proper meals at home or school, thereby showing a permissive attitude about food.

The children eat too much, but that's because during school break they come to the center without eating breakfast or even dinner the previous evening [...] It's hard to tell the kids who eat two to three servings not to do so. [P2-1]

\section{Assistant cooks}

The participants noted that the personnel from the government who prepare the food (i.e. assistant cooks) often have little or no knowledge of what child meal service at the center entails and tend to follow their own tastes and recipes, negatively affecting desirable eating habits in children. The service providers perceived that the assistant cooks lack a sense of responsibility. 
The previous assistant cook would buy groceries according to her own recipes and didn't use written recipes because she could not read Korean. [...] We always have to ask them to make the food less salty. [P1-5]

The assistant cooks are either full or conditional recipients of basic livelihood security, so they still get paid a certain amount whether they come to work or not. They'll come to work and then stop showing up, even though eating is naturally important to the children. [P1-6]

\section{Possible solutions at the CCC-centers}

Possible solutions proposed by the service providers are related to more (professional) personnel, increased budgets, and support from the government.

\section{Personnel}

The service providers pointed out that the presence of a professional nutritionist is crucial. They expressed the importance of quality management, such as checking sodium levels, meal portions, and recipes.

Additionally, more (reliable) personnel and clear job descriptions might help improve the situation at CCC-centers. In that case, there would be no diffusion of responsibility, and more adequate supervision. Teachers at CCC-centers pointed out the absolute lack of personnel, explaining how they themselves sometimes even go out to buy groceries and prepare meals. "From the children's perspective, the teachers need to join them at mealtime, but it's difficult to do so. There is so much paperwork that needs to be done." [P2-2]

\section{Governmental support}

Initiated by the government, there are programs, projects, and interventions focused on CCC-centers. The participants noted that these initiatives should have longer durations.

Health promotion projects need to be continuous and results should not be expected within one or two years. [...] It is unlikely that children's health will improve immediately. Projects need to be started and maintained in preschool or at an even younger age to realize health benefits. [P3-1]

\section{Monetary support}

Various institutions provide meal plans for daily 4,000 won ( $€ 3$ or \$3.5) per person for meal service management in the CCC-centers, but it is difficult to prepare food in accordance with the meal plans provided. Participants expressed the need for the provision of meal plans that take the cost of groceries into account. "I was trying to buy groceries according to the meal plan, but we have 20 people and it is impossible to match the meal plan with 80,000 won." [P1-5] 


\section{The system level}

Participants point out that certain needs arise when they work in the field at CCC-centers, but the government or CCC-center headquarters proceed with government policies or projects that do not reflect reality. These circumstances make their work in the field more challenging and reduce efficiency.

Government policies do not align with what we need. What we really need is a cook. However, the government does not want to send us cooks, and instead sends recipients of basic livelihood security with the aim of improving employment. The local government informs us that a recipient has been dispatched, but that individual does not show up. The policies do not suit our needs. [P1-2]

Children spend their time at home, school, and the CCC-centers. However, the service providers explain that there is no connection between these three environments. This prevents children from forming healthy eating habits.

Most children are picky eaters. In our case, we make it a rule for the kids to try everything prepared for a balanced diet. When they go home, however, that diet is disrupted. The mothers don't appreciate it if we tell them to try harder ... That makes it difficult for us to give meal guidance. [P2-3]

It would be nice if the school, center, and parents could be connected ... the CCCcenters could serve as a link between the school and the parents. [P2-6]

\section{Discussion}

We identified socio-ecological barriers (based on the perspectives of CCC service providers) that influence eating habits of low-income children attending CCC-centers. Service providers perceived the increase in obesity among children from low-income families as a common issue, affected by various socioecological factors. To enhance children's health, it is necessary to consider the interactions among systems at a variety of levels, for example, local community and health care policies (Kok, Peters, and Ruiter 2017; Park 2018; Sallis, Owen, and Fisher 2015).

Participants reported that the eating habits of children attending CCC-centers involved overeating, unbalanced diets, eating in a hurry, and preference for salty food. An earlier study of dietary behaviors of children in low-income families in South Korea showed problematic eating behaviors, such as unbalanced diets, eating meals in a hurry, skipping breakfast, and irregular meal times (Park, Han, and Kim 2011). Reasons for such behaviors included lack of self-regulation, risk perception and coping skills. On the individual level, evidence shows that children with poor eating self-regulation are at a higher risk of becoming overweight and obese (Anderson and Keim 2016; Graziano, Calkins, and Keane 2010), which is linked to unhealthy eating patterns (Goossens et al. 2009; Nguyen-Michel, Unger, and Spruijt-Metz 2007). Children in low-income 
families have difficulties in both self-regulation skills and healthy eating habits (Wang and Lim 2012).

In addition, children from low-income families may experience high levels of stress and poor mental health (e.g., anxiety, depression) owing to the financial and emotional pressures of food insecurity, lack of access to health care, poor housing, and neighborhood violence, among other factors (Poole-Di Salvo, Silver, and Stein 2016). Relieving their stress by eating can lead to obesity (Turton, Chami, and Treasure 2017). The ability to cope with such stress factors is related to psychological adaptation. Michopoulos et al. (2015) reported that if people are exposed to stress or trauma in childhood, they experiences depression symptoms and emotional dysregulation, thereby developing the habit of emotional eating. Stress coping education for children from low-income families improves coping skills while lowering psychosocial stress (Wadsworth et al. 2011). Therefore, providing primary care providers and children attending CCC-centers with interventions regarding skills for coping with stress can help steer children toward healthy eating habits.

Children's homes and the parenting they receive are important social aspects that influence health behaviors (Lindsay et al. 2018). In the current study, negligence, lack of money, permissive parenting, and parental habits was the main factors among interpersonal level to influence children's unhealthy eating habits. Because there is no one at home, these children cook and eat instant noodles, or whatever they find in the refrigerator, and this reflects the reality of socially vulnerable families in Korea. It is difficult for those parents to regularly prepare meals for children because they work too long to make ends meet, and children inevitably eat irregularly because their parents return home late (Park, Han, and Kim 2011).

It is necessary to teach the primary caregivers that in order for children to improve their nutritional status and develop healthy eating habits, they cannot be left unattended. Practical interventions are required so that parents can prepare in advance for children to have nutritionally balanced meals, even when their caregivers are not at home. Lovelace and Rabiee-Khan (2013) showed that parents from low-income families want to provide their children with healthy diets but lack the necessary knowledge. Offering appropriate support and information can contribute to improving children's diets. When parents do not have enough time to care for their children because of work, enabling them to prepare healthy meals using some very simple recipes and skills would relieve the burden of the primary caregiver.

At the organizational level, the permissive attitude of service providers and the incapability of assistant cooks at CCC-centers were the main themes. In Korea, CCC-centers provide an environment that influences the health and development of socially vulnerable children, as well as their socialization and emotional development (Park, Baek, and Im 2018). However, service providers, who have a substantial influence on children's 
health behavior, have a permissive attitude about portion restriction because they sympathize with the children. Wang and Fielding-Singh (2018) reported that adolescents who had health-oriented food rules at home made healthier snack choices, whether or not they had active parental oversight; they also hold beliefs that may correspond to healthier independent dietary choices. These results imply that rules or guidelines are required for children to develop healthy habits. Modeling healthy eating and providing nutrition education are associated with dietary intake in childcare centers, highlighting the role that educators play in shaping children's eating habits (Ward et al. 2017). In addition, recent research showed that nutrition education for service providers at CCC-centers to increase the awareness and self-efficacy on the management of child's eating improved children's eating behaviors at center (Park 2019). This implies the significance of the role and perceptions on child's eating among service providers at CCC centers. Therefore, service providers should have enhanced perceptions on this issue, show consistent concern, and provide regular guidance.

Children attending CCC-centers consume as much as one or two-thirds of their daily dietary requirements while in care. However, meal services in CCC-centers are managed by assistant cooks, who often provide foods that are inconsistent with guideline recommendations. Assistant cooks are recipients of the Basic Likelihood Security System, with little or no knowledge of child health management, while they play a key role in what is served in institutional childcare services (Seward et al. 2017). Strategies such as the provision of resources, professional development opportunities, and role modeling may be particularly important in efforts to address food security and healthy eating behaviors (Michie et al. 2005). Educational programs are needed so that assistant cooks can develop competencies and an increased sense of responsibility.

In developing eating habits, children are affected at the individual, parenting, and CCC-center level. However, there is no system to respond to any vulnerabilities these children may have. CCC-center service providers pointed out the lack of connection between the home, school and center, and the fact that CCC policies do not reflect the situation in the field. This is consistent with the social ecological model suggesting that health is best understood within an ecological context. Building a closely connected network among parents, schools, and care facilities is important as it directly affects the health management of children (Crowley and Sabatelli 2008; Townsend and Foster 2013). Currently, however, schools and CCC-centers in South Korea are managed by different entities and there are no detailed guidelines on children's health management, while education on dietary behaviors is not being offered sufficiently. 
For the establishment of healthy eating guidelines, a collective shift away from current eating patterns is needed across all segments of society (US Department of Health and Human Services 2017). In addition, the Korean government established national eating guidelines to improve balanced nutrient intake, proper eating behaviors, and dietary safety for all populations and societies (Ministry of Health and Welfare 2016). Epstein and Sanders (2002) suggested the need to redesign policies and practices that link schools, families, and communities; shared responsibilities and overlapping influence mean that parents do not bear the entire burden of determining how to guide their children. Furthermore, in South Korea, the government and obesity-related organizations have started to recognize the importance of collaboration among home, school and community, and to emphasized the practice in real life for the prevention and management of obesity (Park et al. 2017). Since children attending CCCcenters spend most of their after-school life there, it is necessary to develop practical health management programs that reflect children's characteristics and environments. It is also necessary to devise and expand communication channels between families, schools, and CCC-centers. This may lead to a more cooperative network whereby parents feel less burdened in raising their children, and all the participants can benefit. Furthermore, sustainability is the core of a successful health-related intervention program (Black et al. 2015; Davis, Spaniol, and Somerset 2015). The effectiveness of health behavior programs depends on the continuous implementation and integration of measures aimed at reaching participants directly and indirectly through their social environments (Vitória, Silva, and Vries 2011). Evidence-based and continuous programs, not one-off programs, need to be developed and implemented.

In other countries, childcare health consultant systems have been established: health care professionals who have completed special training programs provide various health services to children, parents, family members, and those working at childcare facilities (Crowley and Sabatelli 2008). Moreover, educational programs developed by pediatric nursing experts are provided to child health care specialists in the form of continuing education, and have shown to be effective (Benjamin et al. 2008; Crowley and Kulikowich 2009; Hanna et al. 2012). The South Korea government has started "Dream Start" project since 2007, adopted from "Head Start" in the United States and "Sure Start" in the United Kingdom, to support education, welfare, and health for children from disadvantaged families. However, unfortunately, these community-based system at health care sectors to prevent and management childhood disease is under-developed and the participants had low satisfaction to this project (Kim 2013). We need a comprehensive and systematic strategy to control and manage health care as well as the eating habits of children by establishing a network for health management specialists to reestablish the severed link between family, school, and CCC-centers. 


\section{Limitations}

This study did not include the perspectives of stakeholders in other areas that could influence children. In future research, it is necessary to study the perceptions of school teachers and of parents, thereby comparing and contrasting their perspectives.

\section{Future directions and implications}

This study provides information on the development of CCC-center programs to improve the eating habits of children from low-income families, who often spend more time at CCC-centers than they do at home. There is sufficient evidence for the effectiveness of health care professionals as a child health consultants providing various health services to children, parents, families and childcare workers (Benjamin et al. 2008; Crowley and Kulikowich 2009; Crowley and Sabatelli 2008; Hanna et al. 2012), indicating the important role of them in the community setting. Active involvement of health care professionals and experts should be emphasized to improve healthy eating habits of CCC children, while they need to build a partnership and establish a well-connected system to manage children's health.

Further research is needed to explore the factors that can influence children's health behaviors from a more diversified view in areas such as children, parents, school teachers, or policymakers. The issue of malnutrition has also been rising as a major problem, so further research on the nutritional status and quality of nutrition of children from low-income families is required.

\section{Conclusion}

For developing interventions and future implementation of those interventions, a first step is to identify all stakeholders related to the problem and possible solutions. Our study found that the eating habits of children in CCC-centers were associated with individual and environmental factors surrounding children. Our findings provide a foundation for healthcare providers, policymakers, researchers, and other stakeholders to discuss how to better address low-income children's eating habits to improve their obesity or health. To enhance healthy eating habits of low-income children, multilevel interventions including children, parents, schoolteachers, and CCC service providers are needed. Moreover, all the related departments were functioning separately, so children experienced difficulties and limitations in developing proper eating habits. Continuous and responsible health management programs, connecting family, school, and community, should be promoted to enhance their healthy eating habits. 


\section{Declaration of conflicting interests}

The author(s) declared no potential conflicts of interest with respect to the research, authorship, and/or publication of this article.

\section{Funding}

This work was supported by the National Research Foundation of Korea (NRF) grant funded by the Korea government (MSIP) [No. 2015R1C1A1A01052892].

\section{ORCID}

Jiyoung Park (D) http://orcid.org/0000-0003-1374-9187

G. A. Ten Hoor (10) http://orcid.org/0000-0001-5500-1893

Jeonghyun Cho (D) http://orcid.org/0000-0003-4492-1197

\section{References}

Anderson, S. E., and S. A. Keim. 2016. Parent-child interaction, self-regulation, and obesity prevention in early childhood. Current Obesity Reports 5 (2):192-200. doi:10.1007/s13679016-0208-9.

Benjamin, S. E., D. F. Tate, S. I. Bangdiwala, B. H. Neelon, A. S. Ammerman, J. M. Dodds, and D. S. Ward. 2008. Preparing childcare health consultants to address childhood overweight: A randomized controlled trial comparing web to in-person training. Maternal and Child Health Journal 12 (5):662-69. doi:10.1007/s10995-007-0277-1.

Black, J. L., C. E. Velazquez, N. Ahmadi, G. E. Chapman, S. Carten, J. Edward, S. Shulhan, T. Stephens, and A. Rojas. 2015. Sustainability and public health nutrition at school: Assessing the integration of healthy and environmentally sustainable food initiatives in Vancouver schools. Public Health Nutrition 18 (13):2379-91. doi:10.1017/ S1368980015000531.

Crowley, A. A., and J. M. Kulikowich. 2009. Impact of training on childcare health consultant knowledge and practice. Pediatric Nursing 35 (2):93-100.

Crowley, A. A., and R. M. Sabatelli. 2008. Collaborative childcare health consultation: A conceptual model. Journal for Specialists in Pediatric Nursing 13 (2):74-88. doi:10.1111/j.1744-6155.2008.00139.x.

Dachner, N., L. Ricciuto, S. I. Kirkpatrick, and V. Tarasuk. 2010. Food purchasing and food insecurity among low-income families in Toronto. Canadian Journal of Dietetic Practice and Research 71 (3):e50-6. doi:10.3148/71.3.2010.127.

Davis, J. N., M. R. Spaniol, and S. Somerset. 2015. Sustenance and sustainability: Maximizing the impact of school gardens on health outcomes. Public Health Nutrition 18 (13):2358-67. doi:10.1017/S1368980015000221.

Epstein, J., and M. G. Sanders. 2002. School, family, and community partnerships. In Education and sociology, ed. D. Levinson, P. Cookson, and A. Sadovnik, 525-32. New York: Routledge Falmer Press.

Goossens, L., C. Braet, L. Van Vlierberghe, and S. Mels. 2009. Loss of control over eating in overweight youngsters: The role of anxiety, depression and emotional eating. European Eating Disorder Review 17 (1):68-78. doi:10.1002/erv.892. 
Graziano, P. A., S. D. Calkins, and S. P. Keane. 2010. Toddler self-regulation skills predict risk for pediatric obesity. International Journal of Obesity 34 (4):633-41. doi:10.1038/ ijo.2009.288.

Haerens, L., I. De Bourdeaudhuij, G. Barba, G. Eiben, J. Fernandez, A. Hebestreit, E. Kovács, H. Lasn, S. Regber, M. Shiakou, et al. 2009. Developing the IDEFICS community-based intervention program to enhance eating behaviors in 2-to-8-year-old children: Findings from focus groups with children and parents. Health Education Research. 24 (3):381-93. doi:10.1093/her/cyn033.

Hanna, H., R. Mathews, L. H. Southward, G. W. Cross, J. Kotch, T. Blanchard, and A. G. Cosby. 2012. Use of paid childcare health care consultants in early care and education settings: Results of a national study comparing provision of health screening services among head start and non-head start centers. Journal of Pediatric Health Care 26 (6):427-35. doi:10.1016/j.pedhc.2011.05.008.

Hernandez, V. R., S. Montana, and K. Clarke. 2010. Child health inequality: Framing a social work response. Health \& Social Work 35 (4):291-301. doi:10.1093/hsw/35.4.291.

Jang, B. J. 2019. Losing a place to play, not eating properly: Children hurt by adults' circumstances. Busanilbo, May 2. Accessed January 30, 2020. http://www.busan.com/ view/busan/view.php?code $=2019050219341559778$.

Kim, H. R. 2009. Implication of health behaviors in socioeconomic health inequalities and policy directions. Health and Welfare Policy Forum 149:36-47.

Kim, H. S. 2013. Health disparity and health welfare among children from low-income families. Child Health Nursing Research 19:247-51. doi:10.4094/chnr.2013.19.4.247.

Kim, H. S., J. Park, Y. Ma, and M. Im. 2019. What are the barriers at home and school to healthy eating? Overweight/obese child and parent perspectives. Journal of Nursing Research 27:e48. doi:10.1097/jnr.0000000000000321.

Kim, H-S. 2013. Health disparity and health welfare among children from low-income families. Child Health Nursing Research 19:247-51. doi: 10.4094/chnr.2013.19.4.247.

Kok, G., L. W. Peters, and R. A. Ruiter. 2017. Planning theory-and evidence-based behavior change interventions: A conceptual review of the intervention mapping protocol. Psicologia: Reflexão e Crítica 30:19.

Krueger, R. A., and M. A. Casey. 2014. Focus groups: A practical guide for applied research. California: Sage Publications.

Lee, J. Y., J. Park, H. S. Kim, W. S. Kim, G. Hwang. 2017. Barriers to promoting physical activity among overweight and obese children from low-income families using community childcare centers. Journal of Korean Public Health Nursing 31:327-40.

Lindsay, A. C., S. F. Wallington, F. D. Lees, and M. L. Greaney. 2018. Exploring how the home environment influences eating and physical activity habits of low-income, Latino children of predominantly immigrant families: A qualitative study. International Journal of Environmental Research and Public Health 15 (5):E978. doi:10.3390/ijerph15050978.

Lovelace, S., and F. Rabiee-Khan. 2013. Food choices made by low-income households when feeding their pre-school children: A qualitative study. Maternal \& Child Nutrition 11 (4):870-81. doi:10.1111/mcn.12028.

Magee, C. A., P. Caputi, and D. C. Iverson. 2013. Patterns of health behaviours predict obesity in Australian children. Journal of Paediatrics and Child Health 49 (4):291-96. doi:10.1111/ jpc.2013.49.issue-4.

Michie, S., M. Johnston, C. Abraham, R. Lawton, D. Parker, and A. Walker; "Psychological Theory" Group. 2005. Making psychological theory useful for implementing evidence based practice: A consensus approach. Quality \& Safety in Health Care 14 (1):26-33. doi:10.1136/qshc.2004.011155. 
Michopoulos, V., A. Powers, C. Moore, S. Villarreal, K. J. Ressler, and B. Bradley. 2015. The mediating role of emotion dysregulation and depression on the relationship between childhood trauma exposure and emotional eating. Appetite 91:129-36. doi:10.1016/j. appet.2015.03.036.

Ministry of Health and Welfare 2016. General dietary guidelines for koreans. Seoul: Korea Health Promotion Institute

Nguyen-Michel, S. T., J. B. Unger, and D. Spruijt-Metz. 2007. Dietary correlates of emotional eating in adolescence. Appetite 49 (2):494-99. doi:10.1016/j.appet.2007.03.005.

Oh, Y. M., A. R. Jo, and D. H. Lee. 2018. Obesity fact sheets for national health promotion 2013-2017. Seoul: Korea Health Promotion Institute.

Park, E. Y., S. N. Han, and H. K. Kim. 2011. Assessment of meal quality and dietary behaviors of children in low-income families by diet records and interviews. Korean Journal of Food \& Nutrition 24:145-52. doi:10.9799/ksfan.2011.24.2.145.

Park, J. 2018. Predictors of health-promoting behaviors in children from low-income families: An ecological approach. Nursing and Health Sciences 20 (1):60-68. doi:10.1111/ nhs.2018.20.issue-1.

Park, J. 2019. Strategies for reducing health disparities in childhood obesity: Messages from community-based participatory research. Paper presented at the 2019 International Congress on Obesity and Metabolic Syndrome \& Asia-Oceania Conference on Obesity, Seoul, South Korea, August 30.

Park, J., G. Hwang, and J. Cho. 2018. Barriers and improvements to promoting physical activity among children using community childcare centers: Perspectives of service providers. Journal of Korean Public Health Nursing 32:109-21.

Park, J., H. Ma, Y. Lee, H. Oh. 2017. Trends in intervention study for childhood obesity in Korea. Child Health Nursing Research 23 23:81-90. doi:10.4094/chnr.2017.23.1.81.

Park, J., S. Baek, and M. Im. 2018. Trends in health-related interventions on children attending community child care centers in South Korea. Child Health Nursing Research 24:241-51. doi:10.4094/chnr.2018.24.2.241.

Park, S. H., and H. A. Jung. 2017. Investigation of the management of foodservice facilities in community child centers in Daegu and Gyeongbuk area. The East Asian Society of Dietary Life 27 (4):459-72. doi:10.17495/easdl.2017.8.27.4.459.

Poole-Di Salvo, E., E. J. Silver, and R. E. Stein. 2016. Household food insecurity and mental health problems among adolescents: What do parents report? Academic Pediatrics 16 (1):90-96. doi:10.1016/j.acap.2015.08.005.

Rauch, S. A., and B. P. Lanphear. 2012. Prevention of disability in children: Elevating the role of environment. The Future of Children 22 (1):193-217. doi:10.1353/foc.2012.0006.

Ritchie, J., and L. Spencer. 1994. Qualitative data analysis for applied policy research. In Analysing qualitative data, ed. A. Bryman and R. G. Burgess, 173-94. London: Routledge.

Sallis, J. F., N. Owen, and E. Fisher. 2015. Ecological models of health behavior. In Health behavior: Theory, research, and practice, ed. K. Glanz, B. K. Rimer, and K. Viswanath, 43-64. San Francisco: Jossey-Bass.

Seward, K., M. Finch, S. L. Yoong, R. Wyse, J. Jones, A. Grady, J. Wiggers, N. Nathan, K. Conte, and L. Wolfenden. 2017. Factors that influence the implementation of dietary guidelines regarding food provision in centre based childcare services: A systematic review. Preventive Medicine 105:197-205. doi:10.1016/j.ypmed.2017.09.024.

Suh, H. J., and S. H. Rho. 2013. Children-youths and parents' selection criteria of community children's center. Korean Journal of Youth Studies 20:167-89.

Townsend, N., and C. Foster. 2013. Developing and applying a socio-ecological model to the promotion of healthy eating in the school. Public Health Nutrition 16 (6):1101-08. doi:10.1017/S1368980011002655. 
Trofholz, A. C., A. D. Tate, M. L. Draxten, S. S. Rowley, A. K. Schulte, D. Neumark-Sztainer, R. F. MacLehose, and J. M. Berge. 2017. What's being served for dinner? An exploratory investigation of the associations between the healthfulness of family meals and child dietary intake. Journal of the Academy of Nutrition and Dietetics 117 (1):102-09. doi:10.1016/j.jand.2016.08.006.

Turton, R., R. Chami, and J. Treasure. 2017. Emotional eating, binge eating and animal models of binge-type eating disorders. Current Obesity Reports 6 (2):217-28. doi:10.1007/ s13679-017-0265-8.

US Department of Health and Human Services. 2017. Dietary guidelines for Americans 2015-2020. New York: Skyhorse Publishing Inc.

Vitória, P. D., S. A. Silva, and H. D. Vries. 2011. Longitudinal evaluation of a smoking prevention program for adolescents. Revista de Saude Publica 45 (2):344-54. doi:10.1590/ S0034-89102011000200013.

Wadsworth, M. E., C. D. Santiago, L. Einhorn, E. M. Etter, S. Rienks, and H. Markman. 2011. Preliminary efficacy of an intervention to reduce psychosocial stress and improve coping in low-income families. American Journal of Community Psychology 48 (3-4):257-71. doi:10.1007/s10464-010-9384-z.

Wang, J., and P. Fielding-Singh. 2018. How food rules at home influence independent adolescent food choices. Journal of Adolescent Health 63 (2):219-26. doi:10.1016/j. jadohealth.2018.02.010.

Wang, Y., and H. Lim. 2012. The global childhood obesity epidemic and the association between socio-economic status and childhood obesity. International Review of Psychiatry 24 (3):176-88. doi:10.3109/09540261.2012.688195.

Ward, S., M. Blanger, D. Donovan, H. Vatanparast, N. Muhajarine, R. Engler-Stringer, A. Leis, M. L. Humbert, and N. Carrier. 2017. Association between childcare educators' practices and preschoolers' physical activity and dietary intake: A cross-sectional analysis. BMJ Open 7 (5):e013657. doi:10.1136/bmjopen-2016-013657.

World Obesity. Overweight/obesity by socio-economic status-children. Global obesity observatory. Accessed August 25, 2018. https://www.worldobesity.org/data/map/economicstatus-children. 